\section{Progressive pituitary hyperplasia over the course of 2 years demonstrated on magnetic resonance imaging in a patient with long standing, profound primary hypothyroidism}

\author{
Kathryn Stephens,1 Jerome Rusin,² \\ Sasigarn A. Bowden 1 \\ 1Division of Endocrinology, Metabolism \\ and Diabetes, Nationwide Children's \\ Hospital, Columbus, OH; 2Section of \\ Diagnostic Radiology, Nationwide \\ Children's Hospital, Columbus, OH, USA
}

\section{Abstract}

Pituitary hyperplasia secondary to primary hypothyroidism and subsequent regression following thyroid replacement has been well described. We report a 12 year-old male who was retrospectively found to have progressive pituitary hyperplasia over the course of 2 years prior to his diagnosis of primary hypothyroidism, as documented on annual brain magnetic resonance imaging (MRI) for Arnold Chiari Type 1 malformation. He presented to Endocrinology with a 2-year history of fatigue, worsening daily headaches and linear growth deceleration. The diagnosis of primary hypothyroidism as the cause for his pituitary hyperplasia was made. He was started on levothyroxine with subsequent regression of pituitary hyperplasia demonstrated on repeat brain MRI six months later. This case is the first that demonstrates progressive pituitary hyperplasia from early in the course to diagnosis of hypothyroidism. It also illustrates that pituitary hyperplasia noted on routine brain MRI can be a presenting sign of primary hypothyroidism that should prompt endocrinologic evaluation.

\section{Introduction}

Pituitary hyperplasia secondary to primary hypothyroidism has been well described and documented by magnetic resonance imaging (MRI) in the literature.1-6 Long standing hypothyroidism leads to hyperplasia of the thyrotroph cells of the anterior pituitary due to loss of negative feedback inhibition to the hypothalamus, resulting in progressive enlargement of the pituitary gland. Subsequent thyroid replacement therapy has been shown to result in complete regression of pituitary enlargement.1-6 We report a 12 yearold male who was retrospectively found to have progressive pituitary hyperplasia over the course of 2 years prior to his diagnosis of primary hypothyroidism which resolved with thyroid replacement therapy.

\section{Case Report}

A 12 year old male with Arnold Chiari Type 1 malformation was referred to Endocrinology after pituitary hyperplasia was noted on his annual brain MRI obtained for routine monitoring of his anatomic abnormalities. His presenting symptoms included a 2-year history of fatigue, dry skin, cold intolerance, and poor linear growth prior to seeking medical attention. He also had a history of worsening daily headaches, which were initially attributed to his Chiari malformation. On physical examination, his height was $145.1 \mathrm{~cm}$ (10 $10^{\text {th }}$ percentile) and weight $41.9 \mathrm{~kg}$ (16 $6^{\text {th }}$ percentile). Review of his growth curve revealed linear growth deceleration, dropping from the $60^{\text {th }}$ percentile to the $10^{\text {th }}$ percentile for length over the prior 2 years. His face appeared slightly puffy and his hair was dry and coarse. The thyroid gland was unremarkable and was not palpable. His neurological exam was normal including fundoscopic exam and visual field testing. Pubertal staging was consistent with tanner stage 2 pubic hair with early pubertal appearance of his phallus and scrotum. Testes were descended and $8 \mathrm{ml}$ bilaterally. A bone age was delayed at 10 years at a chronological age of 12 years and 8 months (-3.4 standard deviation). Retrospective review of his 3 prior brain MRI scans showed progressive pituitary enlargement. A brain MRI at age 10 years showed an enlarged pituitary gland measuring $7.81 \times 9.38 \mathrm{~mm}$; nearly twice the size of a normal prepubertal gland of $<5 \mathrm{~mm} .^{7}$ A subsequent annual brain MRI at age 11 years (or a year prior to diagnosis) showed marked pituitary hyperplasia, as it had doubled in size from the previous year, to $13.39 \times 16.89 \mathrm{~mm}$. His 3rd MRI just prior to referral revealed an even more hypertrophied pituitary gland, measuring $15 \times 17.21 \mathrm{~mm}$ (Figure 1). The diagnosis of primary hypothyroidism as the cause for his pituitary gland hypertrophy was confirmed by a markedly elevated TSH value of $966 \mathrm{uIU} / \mathrm{mL}$ (normal range 0.5-5 uIU/mL) and undetectable free $\mathrm{T} 4<0.03 \mathrm{ng} / \mathrm{dL}$ (normal range 0.7-2.0 $\mathrm{ng} / \mathrm{dL}$ ). Anti-thyroglobulin antibody was positive at 4156 (normal $<50 \mathrm{IU} / \mathrm{mL}$ ) which confirmed Hashimoto's thyroiditis. A prolactin level was obtained and found to be slightly elevated at 43 (normal range $2-19 \mathrm{ng} / \mathrm{mL}$ ) although our patient denied a history of galactorrhea. Transaminases were slightly elevated, as were total cholesterol and triglycerides
Correspondence: Kathryn Stephens, 700 Children's Drive, Columbus, Ohio 43205, USA.

Tel. +1.614.7224425 - Fax: +1.614.7224440

E-mail: kathryn.stephens@nationwidechildrens.org

Key words: pituitary hyperplasia, hypertrophy, hypothyroidism.

Conflict of interests: the authors report no conflicts of interests.

Received for publication: 28 September 2012. Revision received: 7 November 2012.

Accepted for publication: 12 November 2012.

This work is licensed under a Creative Commons Attribution NonCommercial 3.0 License (CC BYNC 3.0).

(C) Copyright K. Stephens et al., 2013

Licensee PAGEPress, Italy

Endocrinology Studies 2013; 3:e2

doi:10.4081/es.2013.e2

(Table 1). The remainders of his endocrine function studies are listed in Table 1.

Treatment was initiated with levothyroxine $25 \mathrm{mcg}$ daily initially for 2 weeks, and then increased to $50 \mathrm{mcg}$ daily. The dose was further increased to $75 \mathrm{mcg}$ daily after 1 month, and again increased to $88 \mathrm{mcg}$ daily after 9 months of treatment based on repeat thyroid function results. After initiation of levothyroxine therapy, our patient had subsequent resolution of his symptoms including fatigue, dry skin, cold intolerance and headaches. He assumed a normal growth velocity and displayed adequate catch up growth. Other repeat lab work demonstrated resolution of his hyperprolactinemia, transaminitis, and hyperlipidemia after 4 months of treatment (Table 1). Complete regression of his pituitary hyperplasia was demonstrated on repeat brain MRI six months after initiation of treatment with thyroid replacement (Figure 1).

\section{Discussion}

Acquired primary hypothyroidism in children and adolescents most often is caused by autoimmune, chronic lymphocytic thyroiditis (Hashimoto's thyroiditis) mediated by lymphocytic infiltration of the thyroid gland. Infiltration of the thyroid tissues leads to progressive dysfunction of thyroid hormone synthesis and secretion, leading to end-organ failure. The loss of thyroxine negative feedback to the hypothalamus and pituitary gland leads to increased thyroid releasing hormone (TRH) and secondary hypertrophy of the thyrotrophic cells in the anterior pituitary, leading to enlargement of the gland. ${ }^{8}$ Pituitary enlarge- 
ment secondary to primary hypothyroidism was first observed by Niepce in 1851 during the autopsy of a cretin..$^{9}$ Since that time, many reports have documented imaging displaying enlargement of the sellar region in both children and adults. In 1972, Desai and Joshi first reported radiographic evidence of enlarged sellar regions in $61 \%$ of children with hypothyroidism. ${ }^{10}$

Although sellar enlargement has been found to be common in children with primary hypothyroidism, children typically present with subtle signs and symptoms of hypothyroidism, rather than neurological symptoms secondary to sellar expansion. This is in contrast to adults with primary hypothyroidism who more commonly present with symptoms associated with sellar enlargement, such as headache and visual field deficits. Although our patient did present with worsening daily headaches in the absence of other neurological symptoms likely due to sellar expansion; this complaint could have easily been mistaken for a symptom associated with Chiari syndrome. However, in contrast, headaches in association with Chiari syndrome due to Chiari malformation are classically tussive in nature and associated with posterior neck pain. ${ }^{11}$ Other signs and symptoms in adults associated with sellar enlargement may be related to lactotroph hyperplasia including galactorrhea or menstrual irregularities in women; both of which are uncommonly reported in children. This is attributed to the stimulatory effect of TRH on lactotroph cells which may be present in the setting of prolonged hypothyroidism. ${ }^{12}$ Although our patient demonstrated a mild elevation in prolactin, he did not have symptoms of galactorrhea.

The differential diagnosis for an enlarged sella or suprasellar region in children and adolescents noted on brain MRI should include secondary enlargement from any endocrine end-organ dysfunction, in addition to primary hypothyroidism. A reactive enlargement of the pituitary gland has been reported in children with both adrenal and gonadal failure. ${ }^{13,14}$ Furthermore, TSH secreting adenomas and prolactinoma should be considered as well, although TSH secreting adenomas are exceedingly rare in children. Clinicians should also recognize physiological hypertrophy of puberty, which is more common in females. $7,15,16$ Various causes of sellar enlargement may easily be differentiated with studies of endocrine function including thyroid function tests and/or investigation of the entire pituitary axis, which if obtained in our patient, may have prevented the delay in diagnosis. Appropriate identification and treatment is of utmost importance as it might prevent an unnecessary surgery.

The resolution of pituitary hyperplasia secondary to primary hypothyroidism after sufficient treatment with levothyroxine has been

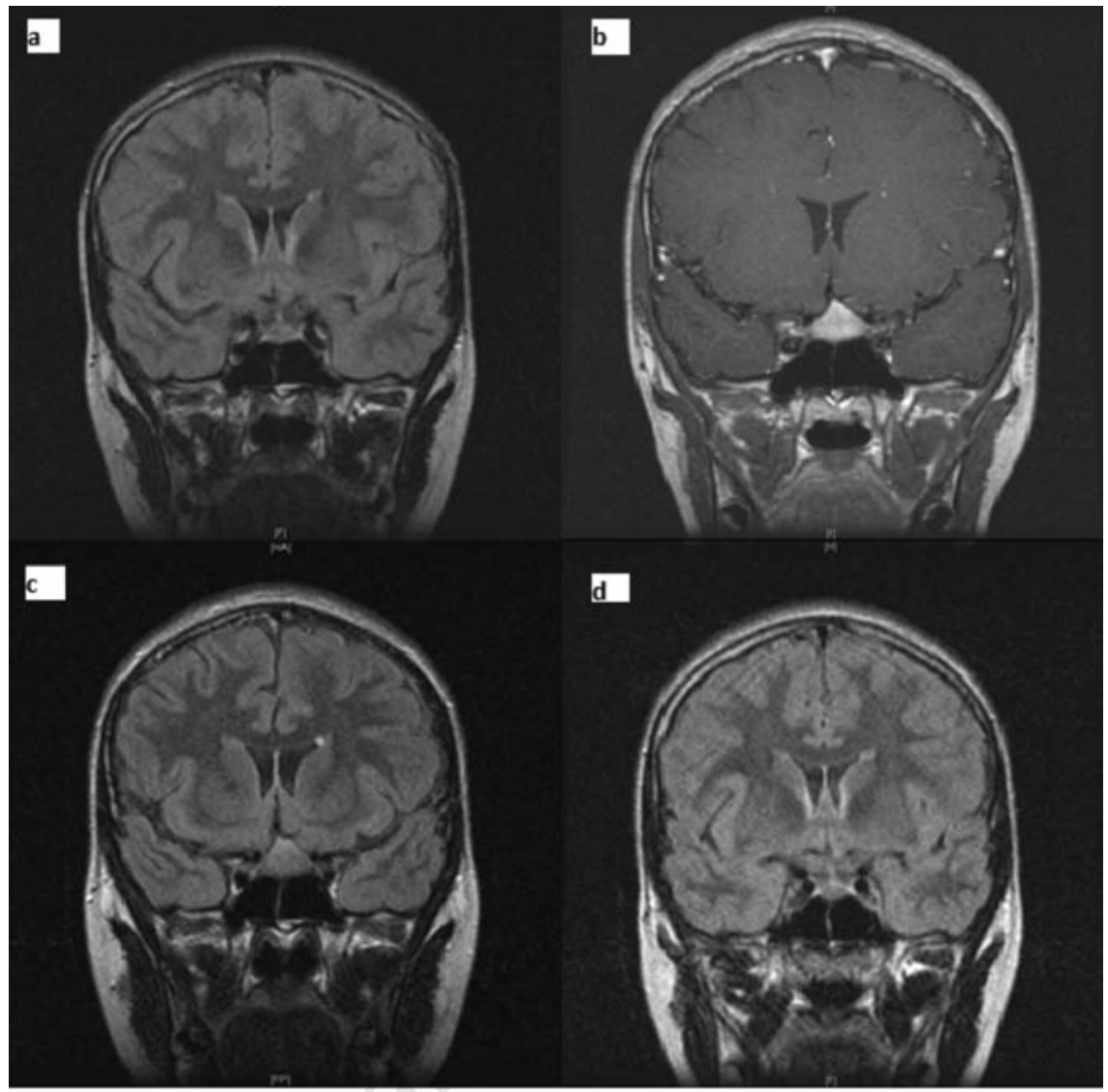

Figure 1. T1-weighted, coronal, unenhanced magnetic resonance imaging that shows progressive pituitary hyperplasia. a) Age 10; 2 years prior to presentation and diagnosis. Pituitary gland measures $7.81 \mathrm{~mm} \times 9.38 \mathrm{~mm}$. b) Age 11; 1 year prior to presentation and diagnosis. Pituitary gland had doubled in size from the previous year, to $14.8 \mathrm{~mm} \mathrm{x}$ $16.9 \mathrm{~mm}$. c) Age 12; just prior to presentation and diagnosis. Pituitary gland measures $15 \mathrm{~mm} \times 17.2 \mathrm{~mm}$. d) Age 12; Resolution of pituitary hyperplasia, 6 months after starting treatment with levothyroxine.

Table 1. Laboratory evaluation at diagnosis and following initiation of treatment.

\begin{tabular}{lcccccc} 
& Diagnosis & 1 mos & 2 mos & 4 mos & 9 mos & Ref. range \\
TSH & 966.00 & 123.95 & 3.67 & 1.65 & 37.00 & $0.465-4.68 \mathrm{mlU} / \mathrm{L}$ \\
Free T4 & $<0.3$ & 0.65 & 1.14 & 1.50 & 1.30 & $0.7-2.1 \mathrm{ng} / \mathrm{dL}$ \\
\hline Anti-thyroglobulin Ab & 4156 & - & - & - & - & $<50 \mathrm{lU} / \mathrm{mL}$ \\
Anti-TPO Ab & 11 & - & - & - & - & $<35 \mathrm{lU} / \mathrm{mL}$ \\
\hline Prolactin & 43 & - & - & 3 & - & $2-19 \mathrm{ng} / \mathrm{mL}$ \\
LH & 1.9 & - & - & - & - & $0.2-4.9 \mathrm{mlU} / \mathrm{mL}$ \\
\hline FSH & 1.5 & - & - & - & - & $1.8-3.2 \mathrm{mlU} / \mathrm{mL}$ \\
Testosterone & 108 & - & - & - & - & $2-58 \mathrm{ng} / \mathrm{dL}$ \\
\hline IGF-1 & 85 & - & - & - & - & $150-830 \mathrm{ng} / \mathrm{mL}$ \\
IGF-BP3 & 2.8 & - & - & - & - & $2.7-8.9 \mathrm{ug} / \mathrm{mL}$ \\
\hline ALT & 125 & - & - & 22 & - & $7-90 \mathrm{U} / \mathrm{L}$ \\
AST & 118 & - & - & 54 & - & $5-60 \mathrm{U} / \mathrm{L}$ \\
\hline Total cholesterol & 272 & - & - & 109 & - & $95-195 \mathrm{mg} / \mathrm{dL}$ \\
Triglycerides & 139 & - & - & 51 & - & $60-134 \mathrm{mg} / \mathrm{dL}$ \\
\hline
\end{tabular}


described in several case reports..$^{1-6}$ The time course to which resolution or near-complete resolution is first demonstrated on brain MR imaging has varied widely between 1 and 6 months of duration; although one case has been shown to resolve within 6 days of thyroid replacement. ${ }^{17}$ There is, however, very limited data on the time course of progression of secondary pituitary hyperplasia due to hypothyroidism. It is not well clarified as to when the pituitary hyperplasia is first demonstrable on MRI following the development of primary hypothyroidism. Moreover, pituitary hyperplasia is often discovered at the time of diagnosis of long-standing hypothyroidism in most reported cases, with prompt thyroid hormone therapy once diagnosed, leaving no opportunity to demonstrate the natural progression of hypertrophy of the pituitary gland. Shimono et al. ${ }^{18}$ reported rapid progression of pituitary hyperplasia in a cohort of patients with thyroid carcinoma who were initially euthyroid, then made iatrogenically hypothyroid prior to iodine $^{131}$ ablation. All subjects were found to have significantly larger pituitary volumes while in the hypothyroid state than in the euthyroid state indicating that rapid progression of pituitary hyperplasia may occur with acute development of iatrogenic hypothyroidism. Our patient was first noted to have pituitary hyperplasia, nearly twice the size of normal, at age 10 years, which is 2 years before his diagnosis of hypothyroidism. This time frame most likely reflects the onset of hypothyroidism as evidenced by his delayed bone age of 10 years and by the fact that his hypothyroid symptoms and growth deceleration began around that same time. This finding supports the aforementioned report by Shimono et al. ${ }^{18}$ in that rapid progression of pituitary hyperplasia can occur early in the course of hypothyroidism. It is also interesting to note that our patient's pituitary gland enlargement progressed rapidly, doubling in size within the first year of his onset of symptoms. To our knowledge, no demonstration of rapid development and progression of pituitary hyperplasia on a serial brain MR imaging secondary to long-standing, undiagnosed primary hypothy- roidism has been reported prior to our observed case.

\section{Conclusions}

To our knowledge, this is the first case report that demonstrates documented progressive pituitary hyperplasia in a child present for 2 years prior to the diagnosis of long-standing, undiagnosed primary hypothyroidism. This case illustrates the importance of recognizing pituitary or sellar enlargement on brain MRI as a presenting sign of primary hypothyroidism that should prompt endocrinolgic evaluation and reaffirms that adequate treatment with sufficient thyroid hormone replacement results in complete resolution of pituitary enlargement.

\section{References}

1. Ashley WW Jr, Ojemann JG, Park TS, Wippold FJ II. Primary hypothyroidism in a 12-year-old girl with suprasellar pituitary mass: rapid regression after thyroid replacement therapy: case report. J Neurosurg 2005;102:413-6.

2. Eom KS, See-Sung C, Kim JD, et al. Primary hypothyroidism mimicking a pituitary macroadenoma: regression after thyroid hormone replacement therapy. Pediatr Radiol 2009;39:164-7.

3. Hopper NW, Albanese A. Primary hypothyroidism in a child mimicking a pituitary macroadenoma. Horm Res 2005;63:61-4.

4. Kuroiwa T, Okabe Y, Hasuo K, et al. MR imaging of pituitary hypertrophy due to juvenile primary hypothyroidism: a case report. Clin Imaging 1991;15:202-5.

5. Lee CY, Hsu HH, Lai HY, Lee ST. Rapid progression of hypothyroidism-related pituitary hyperplasia. J Neurosurg Pediatr 20;2:212-4.

6. Franceschi R, Rozzanigo U, Failo R, et al. Pituitary hyperplasia secondary to acquired hypothyroidism: case report. Ital J Pediatr 2011;37:15.

7. Elster AD, Chen MY, Williams DW 3rd, Key LL. Pituitary gland: MR imaging of physiologic hypertrophy in adolescence. Radiology 1990;174:681-5.

8. Han L, Wang J, Shu K, Lei T. Pituitary tumorous hyperplasia due to primary hypothyroidism. Acta Neurochir (Wien) 2012;154:1489-92.

9. Niepce B. Traite du goiter et du cretinisme. Baillieres Paris 1851;30.

10. Desai MP, Joshi NC. Roentgenologic changes in hypothyroidism (a study of 40 cases). Indian Pediatr 1972;9:201-7.

11. Yassari R, Frim D. Evaluation and management of the Chiari malformation type 1 for the primary care pediatrician. Pediatr Clin North Am 2004;51:477-90.

12. Al-Gahtany M, Horvath E, Kovacs K. Pituitary hyperplasia. Hormones (Athens) 2003;2:149-58.

13. Nelson, DH. Cushing's syndrome--pituitary or adrenal origin? J Chronic Dis 1960;12:499-503.

14. Samaan NA, Stepanas AV, Danziger J, Trujillo J. Reactive pituitary abnormalities in patients with Klinefelter's and Turner's syndromes. Arch Intern Med 1979;139:198201.

15. Aquilina K, Boop FA. Nonneoplastic enlargement of the pituitary gland in children. J Neurosurg Pediatr 2011;7:510-5.

16. Peyster RG, Hoover ED, Viscarello RR, Moshang T, Haskin ME. CT appearance of the adolescent and preadolescent pituitary gland. AJNR Am J Neuroradiol 1983;4:4114.

17. Sarlis NJ, Brucker-Davis F, Doppman JL, Skarulis MC. MRI-demonstrable regression of a pituitary mass in a case of primary hypothyroidism after a week of acute thyroid hormone therapy. J Clin Endocrinol Metab 1997;82:808-11.

18. Shimono T, Hatabu H, Kasagi K, et al. Rapid progression of pituitary hyperplasia in humans with primary hypothyroidism: demonstration with MR imaging. Radiology 1999;213:383-8. 